\title{
The Effects of Atmospheric Pressure Argon Plasma Treated Bovine Bone Substitute on Bone Regeneration
}

\author{
Jong-Ju Ahn ${ }^{1,+}{ }^{\text {, Ji-Hyun Yoo }}{ }^{2,+}{ }^{\text {, Eun-Bin Bae }}{ }^{1,+} \oplus$, Gyoo-Cheon Kim ${ }^{3,4}$, Jae Joon Hwang ${ }^{5}$, \\ Wan-Sun Lee ${ }^{1}$, Hyung-Joon Kim ${ }^{2, *}$ and Jung-Bo Huh ${ }^{1, * \mathbb{D}}$ \\ 1 Department of Prosthodontics, Dental Research Institute, Dental and Life Science Institute, BK21 PLUS \\ Project, School of Dentistry, Pusan National University, Yangsan 50612, Korea; tarov0414@daum.net (J.-J.A.); \\ 0228dmqls@hanmail.net (E.-B.B.); wslee2008@gmail.com (W.-S.L.) \\ 2 Department of Oral Physiology, Dental Research Institute, Dental and Life Science Institute, School of \\ Dentistry, Pusan National University, Yangsan 50612, Korea; firstlove21c@hotmail.com \\ 3 Department of Oral Anatomy and Cell Biology, School of Dentistry, Pusan National University, \\ Yangsan 50612, Korea; ki91000m@pusan.ac.kr \\ 4 Research \& Development Center, FEAGLE Corporation, Yangsan 50614, Korea \\ 5 Department of Oral and Maxillofacial Radiology, School of Dentistry, Pusan National University, Dental \\ Research Institute, Yangsan 50612, Korea; softdent@pusan.ac.kr \\ * Correspondence: hjoonkim@pusan.ac.kr (H.-J.K.); neoplasia96@hanmail.net (J.-B.H.); \\ Tel.: +82-10-6326-4189 (H.-J.K.); +82-10-8007-9099 (J.-B.H.); Fax: +82-55-510-8208 (H.-J.K.); \\ +82-55-360-5134 (J.-B.H.) \\ + These authors contributed equally to this work.
}

Received: 16 October 2019; Accepted: 23 November 2019; Published: 25 November 2019

\begin{abstract}
This study was undertaken to compare new bone formation between non-expired and expired bovine-derived xenogeneic bone substitute (expired, out-of-use period) and to evaluate the efficacy of argon (Ar)-based atmospheric pressure plasma (APP) treatment on expired bone substitute in rat calvarial defect. The groups were divided into (1) Non/Expired group (Using regular xenografts), (2) Expired group (Using expired xenografts), and (3) Ar/Expired group (Using Ar-based APP treated expired xenografts). Surface observation and cell experiments were performed in vitro. Twelve rats were used for in vivo experiment and the bony defects were created on the middle of the cranium. The bone substitute of each group was implanted into the defective site. After 4 weeks, all the rats were sacrificed, and the volumetric, histologic, and histometric analyses were performed. In the results of osteogenic differentiation and mineralization, Non/Expired and $\mathrm{Ar} /$ Expired groups were significantly higher than Expired group $(p<0.05)$. However, there was no significant difference between groups in the animal study $(p>0.05)$. Within the limitations of this study, the surface treatment of Ar-based APP has a potential effect on the surface modification of bone grafts. However, there was no significant difference in bone regeneration ability between groups in vivo; thus, studies on APP to enhance bone regeneration should be carried out in the future.
\end{abstract}

Keywords: atmospheric pressure plasma; argon; xenograft; bone regeneration; bovine bone

\section{Introduction}

In the dental field, various bone substitutes such as autograft, allograft, and xenograft materials have been studied to enhance the cell response and bone formation [1-3]. Among them, xenogeneic bone substitutes harvested from other species are biocompatible and have a similar elastic modulus to that of human alveolar bone, so they have been most frequently used in clinical application [4]. Bio-Oss ${ }^{\circledR}$ (Geistlich Biomaterials, Wolhusen, Switzerland), a well-known commercially available xenograft is an inorganic, chemically-treated bovine bone mineral and has similar chemical compositions, 
morphologies, and ultrastructure to human spongiosa [5]. It has also been reported that Bio-Oss ${ }^{\circledR}$ is a biocompatible, osteoinductive, and osteoconductive material and can sufficiently act as a scaffold for bone-forming cells and bone formation [6-9].

Shelf life, a usage period of materials, is directly related to the quality and safety of biomedical products due to material not being able to retain its physical and mechanical properties after expiration $[10,11]$. Some research has reported on the surfaces of aged medical products that were newly activated by photofunctionalization, and applying this ultraviolet treatment to dental implant surfaces can also enhance the osseointegration and bone growth [12,13]. In addition, since ultraviolet treatment can change the hydrophobic surface to hydrophilic, lots of osteoblastic cells adhere to ultraviolet treated implants $[12,14,15]$.

Another typical way to make the hydrophilic surface is plasma treatment, which can enhance the surface energy of implant biomaterial [16,17]. Atmospheric pressure plasma (APP), an ionized gas, has been applied to medical and dental fields such as whitening, hemorrhage, wound healing, sterilization, and cancer treatments [18-21]. In addition, APP have often been used to modify the surface of biomaterials [22], and a number of studies have examined the APP surface treatment of titanium implants $[18,23,24]$, zirconia ceramics $[25,26]$, and bone graft materials in dentistry $[1,27]$. Bone grafts are usually used to treat dental skeletal problems such as alveolar bone defect [1], and there is a report that bone graft materials treated by APP using argon gas interact strongly and rapidly with osteoblastic cells [27].

Various inert gasses (e.g., argon, helium, oxygen, and ammonia) were used in APP treatments [28]. Argon (Ar) gas was frequently used to generate plasma, especially in use of surface modification, because of its cost-effective and stable properties, and it can generate the plasma at relatively low energy while retaining the useful characteristics of biomaterial [29]. Giro et al. [30] treated Ar-based APP on the surface of a Ca-P coated implant and evaluated this in a beagle canine model. The higher wettability and closer interaction between the implant threads and connective tissue matrix were observed in comparison with control (Ca-P alone), which resulted in improved new bone rate. Furthermore, several researches on Ar plasma treated bone graft materials, such as xenograft and synthetic bone, reported a good cell response in vitro [1,31].

Through the previous studies, we are satisfied that the Ar-based APP treatment can enhance the surface energy of bovine bone mineral. However, there are few studies on the safety of aged bone substitute (expired, out-of-use period) and reactivating it with surface energy enhancement. The purpose of this study was to compare the new bone formation between the non-expired and expired xenografts, and to evaluate the efficacy of Ar-based APP surface treatment on expired bone graft substitute in rat calvarial defect. The null hypotheses of this study were as follows. First, the aged bone graft material has a similar bone regeneration effect to that of the newly produced bone graft material. Second, the APP treatment on the surface aged bone grafts will not be effective in bone regeneration.

\section{Materials and Methods}

\subsection{Bone Graft Materials Treated with Atmospheric Pressure Plasma (APP)}

Bio-Oss ${ }^{\circledR}$ (Geistlich Biomaterials, Wolhusen, Switzerland), a commercially available and deproteinized bovine bone mineral, was used in this study. Non-expired (regular) Bio-Oss ${ }^{\circledR}$ and expired Bio-Oss ${ }^{\circledR}$ were used in Non/Expired and Expired groups, respectively. Expired Bio-Oss ${ }^{\circledR}$ was 2 years passed its validity period. To evaluate the efficiency of APP on expired bone grafts, expired Bio-Oss ${ }^{\circledR}$ treated by atmospheric pressure plasma using argon (Ar) gas (Ar/Expired group). APP was generated through ionization of Ar gas at atmospheric pressure using FG-Explorer (Feagle co., Yangsan, Korea) (system power: $3 \mathrm{kV}_{\mathrm{pp}}$ ). Ar gas flow was set to $5.0 \mathrm{slm}$ (standard liter per minutes) and the flow rate was controlled by a mass flow controller (MFC). Plasma treatment was performed for $2 \mathrm{~min}$. 


\subsection{In Vitro Study}

\subsubsection{Scanning Electron Microscopy (SEM)}

Scanning electron microscopy (SEM) was conducted to observe the effects of APP on the surface morphologies of bone graft materials. The specimens were coated with Au using a sputter coater (SCD 005, BAL-TEC, Wetzlar, Germany), and observed using SEM (Zeiss SUPRA 25, Carl Zeiss SMT, Oberkochen, Germany) at an acceleration voltage of $5.0 \mathrm{kV}$.

\subsubsection{Cell Culture}

Human mesenchymal stem cells (hMSCs; LONZA, Walkersville, MD, USA) were cultured in MSCs growth medium (MSCGM; LONZA) for expansion and examination of proliferation for in vitro study. The medium was changed every 3 to 4 days until reaching $70 \%$ confluence, and finally the sub-cultured cells at passage number 4 were used for all the experiments. For the differentiation of hMSCs into osteoblasts, the cells were induced by osteogenic medium containing ascorbic acid-2-phosphate (Sigma-Aldrich, Milan, Italy), $10 \mathrm{mM} \beta$-glycerophosphate (Sigma-Aldrich) and $100 \mathrm{nM}$ dexamethasone(Sigma-Aldrich) in an alpha-modification of Eagle's medium ( $\alpha$-MEM; Welgene Inc., Deagu, Korea) supplemented with 10\% fetal bovine serum (FBS; Gibco BRL, Carlsbad, CA, USA), $100 \mathrm{U} / \mathrm{mL}$ penicillin, and $100 \mu \mathrm{g} / \mathrm{mL}$ streptomycin (Gibco BRL).

\subsubsection{Cell Proliferation}

Cell proliferation of hMSCs was investigated by using a 3-[4-dimethylthiazol-2-yl]-2,5-diphenyl tetrazolium bromide (MTT; Sigma-Aldrich) assay. The extracts of each group were prepared prior to the cell proliferation assay. In total, $2 \mathrm{~g}$ of three different samples (Non-expired (regular) Bio-Oss ${ }^{\circledR}$, expired Bio-Oss ${ }^{\circledR}$ and expired Bio-Oss ${ }^{\circledR}$ treated with plasma of argon (Ar) gas) were soaked in $10 \mathrm{ml}$ serum-free $\alpha$-MEM and incubation in $5 \% \mathrm{CO}_{2}$ at $37^{\circ} \mathrm{C}$ for $24 \mathrm{~h}$. After the mixture was centrifuged $(1200 \times \mathrm{g})$ for $5 \mathrm{~min}$, the supernatant was stored at $4{ }^{\circ} \mathrm{C}$. The cells $\left(5 \times 10^{3}\right.$ cells/well) were then seeded in triplicate in four different 48 -well culture plates (Nunc, Roskilde, Denmark) and cultured in the previously prepared extracts diluted in $\alpha$-MEM (20\%). The cells were incubated for $0,1,2,3$ days, and the extracts were replaced with serum-free medium containing $30 \mu \mathrm{L} /$ well of MTT solution $(0.5 \mathrm{mg} / \mathrm{mL}$ MTT in PBS). After $3 \mathrm{~h}$ of incubation, the culture medium was removed and $300 \mu \mathrm{L} /$ well of dimethyl sulfoxide (DMSO; DuchefaBiochemie, Haarlem, The Netherlands) was added. Two $100 \mu \mathrm{L} /$ well aliquots were transferred to a 96-well plates (Nunc) and the absorbance rates were determined at $570 \mathrm{~nm}$ wave lengths with an Opsys MR microplate reader (DYNEXTechnologies Inc., Denkendorf, Germany).

\subsubsection{Alkaline Phosphatase (ALP) and Alizarin Red S (ARS) Staining}

ALP and ARS staining were performed to evaluate the osteogenic differentiation of hMSCs. The cells $\left(5 \times 10^{3}\right.$ cells/well) were seeded in the 48-well plates in triplicate and cultured for 4 and 8 days in the osteogenic media containing the previously prepared extracts $(20 \%)$. At day 4 , the early stage of osteogenic differentiation was analyzed by ALP staining kit (Sigma-Aldrich) according to the manufacturer's instructions. At day 8, the late stage of osteogenic differentiation was determined by ARS staining. For the ARS staining, the cells were fixed with $3.7 \%$ formaldehyde for $15 \mathrm{~min}$ and stained with $2 \%$ ARS solution (Sigma-Aldrich) for $30 \mathrm{~min}$ with gentle agitation. The stained cells were visualized with light microscope and the quantification of the staining images were done by using ImageJ software program (U. S. National Institutes of Health, Bethesda, MD, USA).

\subsubsection{Analysis of Real-Time Polymerase Chain Reaction (PCR)}

The expression of osteogenic genes in hMSCs was examined by real-time polymerase chain reaction $(\mathrm{PCR})$ analysis. The cells $\left(5 \times 10^{3}\right.$ cells/well) were seeded in 6 -well plates and cultured in osteogenic media containing the sample extracts (20\%) for 4 and 8 days. Total RNAs were extracted 
from the cells by TRIzol (Life Technologies, Grand Island, NY, USA) and the RNA concentration was confirmed using a NanoDrop ND-1000 spectrophotometer (Technologies Inc., Wilmington, DE, USA). Complementary DNA (cDNA) was synthesized using $1 \mathrm{~g}$ of total RNA. Real-time PCR was performed on ABI 7500 instrument (Applied Biosystems, Carlsbad, CA, USA) according to the manufacturer's protocol, and SYBR Green Master Mix reagents (Kapa Biosystems, Woburn, MA, USA) were used in each reaction. The relative mRNA expression levels of each following genes were normalized to the house keeping gene Actin. The primers were produced by Bionics (Daejeon, Korea) and the selected sequences are listed as follows (Table 1).

Table 1. Primer sequences used for real-time Polymerase Chain Reaction (PCR) analysis.

\begin{tabular}{cc}
\hline Target Genes & Sequences \\
\hline \multirow{2}{*}{ Actin } & F: 5'- ACTCTTCCAGCCTTCCTTCC -3' \\
& R: 5'- TGTTGGCGTACAGGTCTTTG -3' \\
Runx2 & F: 5'- TGCTTTGGTCTTGAAATCACA -3' \\
& R: 5'- TCTTAGAACAAATTCTGCCCTTT -3' \\
BMP2 & F: 5'- AACACTGTGCGCAGCTTCC -3' \\
& R: 5'- CTCCGGGTTGTTTCCCAC - 3' \\
ALP & F: 5'- ATTTCTCTTGGGCAGGCAGAGAGT -3' \\
& R: 5'- ATCCAGAATGTTCCACGGAGGCTT -3' \\
OCN & F: 5'- CAGCGAGGTAGTGAAGAGAC -3' \\
& R: 5'- TGAAAGCCGATGTGGTCAG -3' \\
OPN & F: 5'- AGACACATATGATGGCCGAGG -3' \\
& R: 5'- GGCCTTGTATGCACCATTCAA -3' \\
\hline
\end{tabular}

\subsection{In Vivo Study}

\subsubsection{Experimental Animals}

Twelve 12-13-week-old male Sprague-Dawley rats (250-300 g) were used in this study. Animals were housed in plastic cages ( 3 rats per cage) and given rodent diet and water. The surgical procedure was performed in accordance with the guidelines issued by the Pusan National University Institutional Animal Care and Use Committee (PNU-2018-1977).

\subsubsection{Surgical Procedures}

The surgical site was incised (15 $\mathrm{mm}$ in length), and the skin and periosteum were dissected to expose the calvarial bone. A circular defect $(8 \mathrm{~mm}$ in diameter) was formed in the center of each parietal bone using a trephine bur (3i Implant Innovations Inc., Palm Beach Garden, FL, USA) under saline irrigation (Figure 1a). Bone grafts of each group were placed into the calvarial defect using a micro spoon (Karl Hammacher GmbH Co., Cologne, Germany) (Figure 1b), and then the defect site was covered with a collagen membrane (GCM2030, GENOSS, Suwon, Korea) (Figure 1c). At 4 weeks after surgery, all the rats were sacrificed, and samples of rat cranium were harvested. The obtained specimens were fixed for 2 weeks in neutral buffered formalin solution for volumetric and histomorphometric analyses.
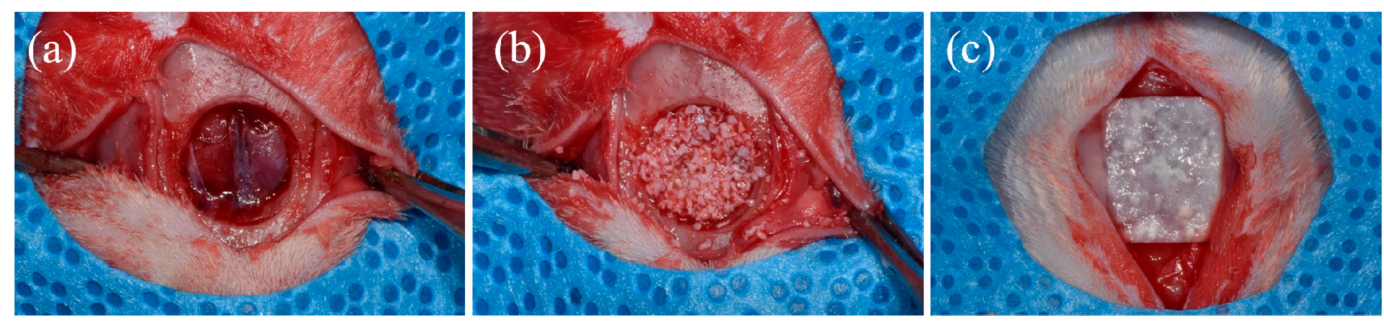

Figure 1. Surgical procedures. (a) Calvarial defects were formed using trephine bur, (b) Bone graft materials were placed into bone defect, (c) A collagen membrane was placed on calvarial defect. 


\subsubsection{Micro-Computed Tomographic (micro-CT) Analysis}

Micro-CT (SMX-90CT; Shimadzu, Kyoto, Japan) was used to measure the new bone volume under the following conditions; $90 \mathrm{kV}$, intensity of $109 \mu \mathrm{A}$, and a pixel spacing of $51 \mu \mathrm{m}$. The three-dimensional micro-CT files were converted to visualized two-dimensional images by a customized-corded-computer program using MATLAB software (MATLAB 2019a, MathWorks, Natick, MA, USA), and the new bone volumes of each calvaria were assessed. The region of interest (ROI) was set equal to a calvaria defect with a diameter of $8 \mathrm{~mm}$ and height of $1.5 \mathrm{~mm}$ (Figure 2).

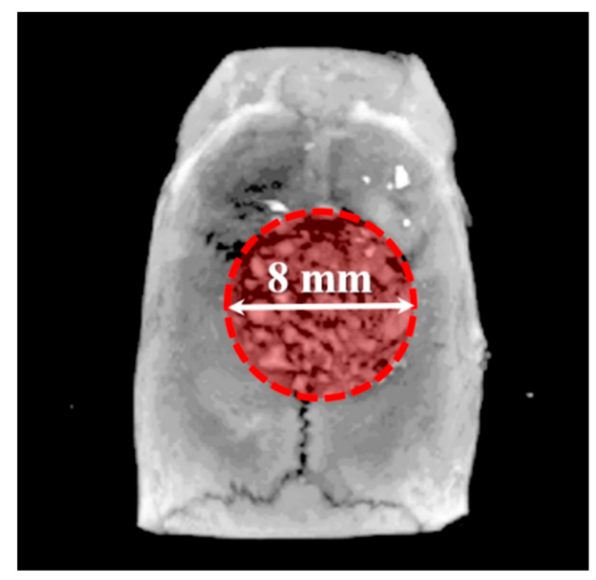

Figure 2. Region of interest (ROI) of bone volume measurement.

\subsubsection{Histologic Specimen Preparation and Histometric Analysis}

Using 17\% ethylenediaminetetraacetic acid (EDTA) solution, specimens were decalcified for 2 weeks. The dehydrated specimens were embedded in paraffin and then sectioned longitudinally into $4 \mu \mathrm{m}$. The slides were stained using hematoxylin-eosin (H\&E) and Masson's trichrome (MT) solutions. The final histologic slides were photographed using an optical microscope (BX51, OLYMPUS, Tokyo, Japan). The photographed images were analyzed by i-Solution ver. 8.1 (IMT Inc., Coquitlam, BC, Canada), and the new bone area percentage in the defect was calculated (Figure 3).

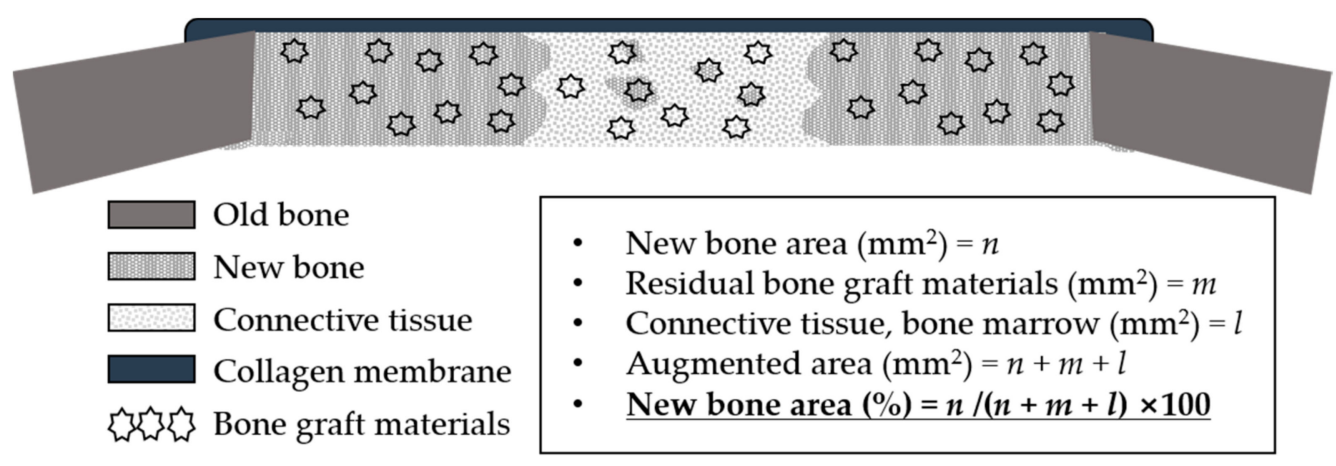

Figure 3. Schematic drawing of the histometric analysis.

\subsection{Statistical Analysis}

All the results were represented as mean \pm standard deviation (SD). The statistical analyses were performed using SPSS ver. 25.0 (SPSS, Chicago, IL, USA). The in vitro and in vivo results were analyzed by Kruskal-Wallis test followed by Mann-Whitney U post-hoc test. The statistical significance was accepted for $p$ values of $<0.05$. 


\section{Results}

\subsection{In Vitro Study}

\subsubsection{Observation of Surface Morphology}

The SEM micrographs at low $(\times 80)$ and high $(\times 8000)$ magnifications showed no difference in similar physical surface morphology in all groups (Figure 4). All the groups exhibit the porous micro rough surface with irregular surface patterns (Figure $4 b, d, f)$.

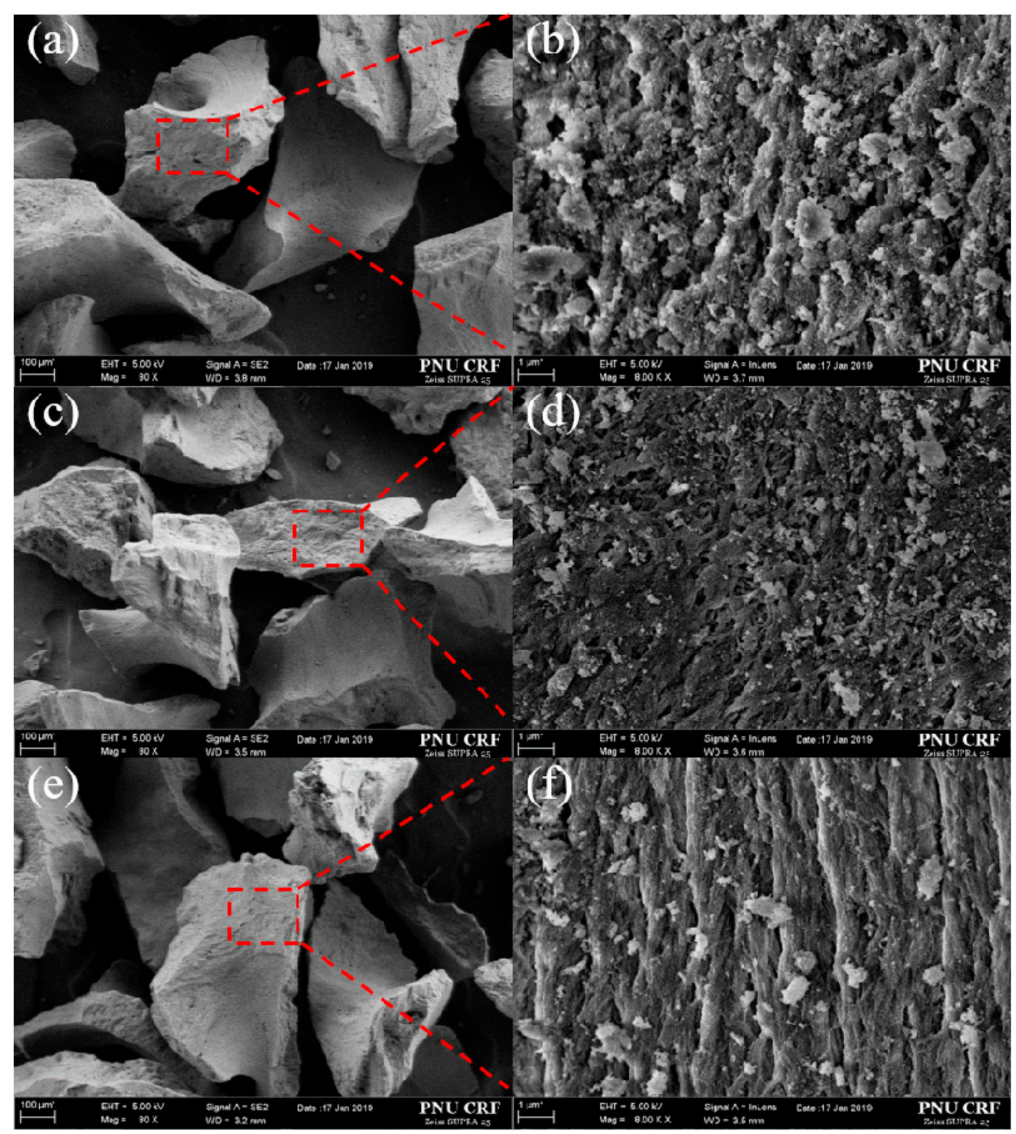

Figure 4. Captured images using scanning electron microscopy. (a,b) Non/Expired group, (c,d) Expired group, (e,f) Ar/Expired group [Original magnification: $\times 80(\mathbf{a}, \mathbf{c}, \mathbf{e}), \times 8000(\mathbf{b}, \mathbf{d}, \mathbf{f})]$.

\subsubsection{Cell Proliferation}

Proliferation rate of hMSCs cultured in different sample extracts was evaluated using an MTT assay. The assay was analyzed spectrophotometrically at 0,1,2, and 3 days after cell seeding (Figure 5). The results reveal the effects of the different extracts on the proliferation of hMSCs at different time points. The cells cultured in the extracts of each group were steadily proliferated from day 0 to day 3 . There was no significant difference in cell proliferation rate between groups $(p>0.05)$.

\subsubsection{Alkaline Phosphatase (ALP) and Alizarin Red S (ARS) Staining}

The ALP and ARS staining was used to analyze the effect of the extracts from different samples on the osteogenic differentiation of hMSCs. The hMSCs were cultured in three different types of extracts for 4 and 8 days (Figure 6a). Upon examination of hMSCs cultured for 4 days, ALP activity increased in the Ar/Expired group compared to the other groups (Figure 6b). At day 8, ARS staining results also confirmed Ar/Expired group showed increase in differentiation compared to the other groups 
(Figure 6c). In both ALP and ARS staining results, there were statically significant differences between the Non/Expired group and Expired group, and Expired group and Ar/Expired group.

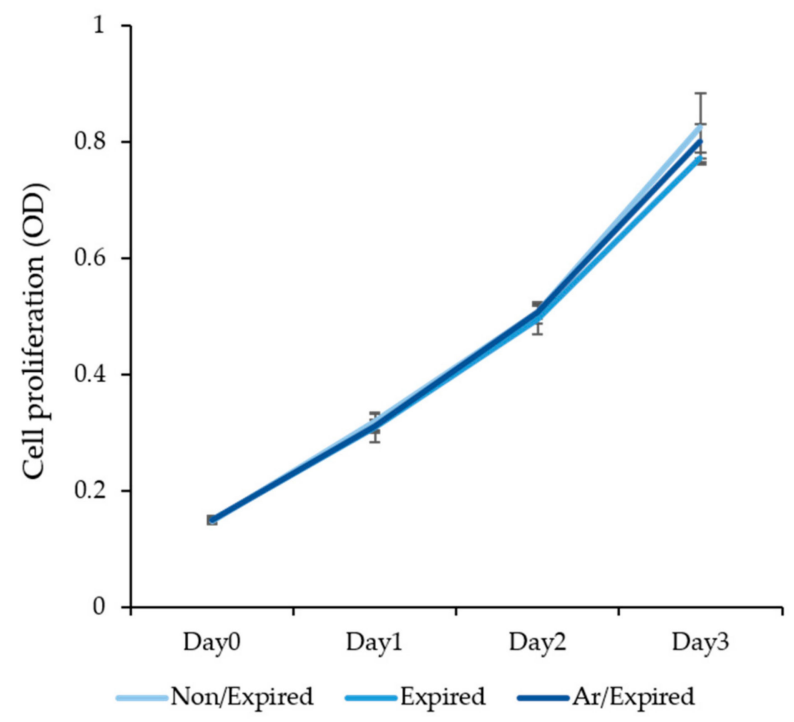

Figure 5. Cell proliferation of human mesenchymal stem cells (hMSCs).

(a)
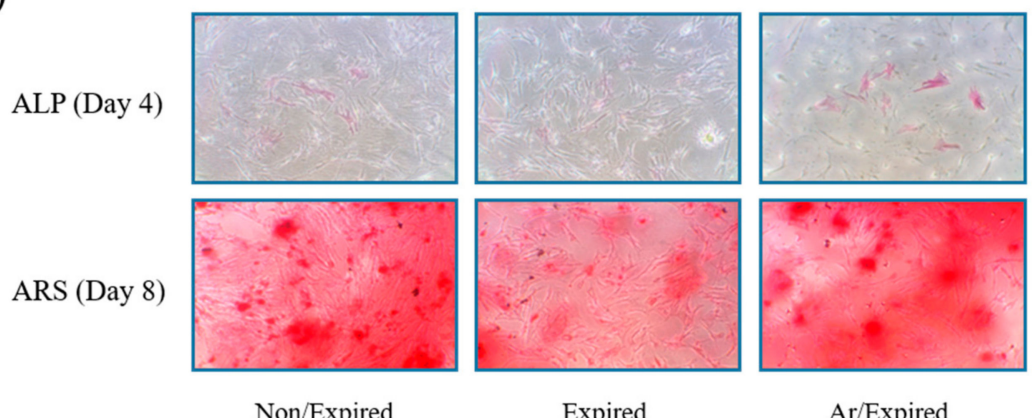

Non/Expired

Expired

$\mathrm{Ar} /$ Expired

(b)

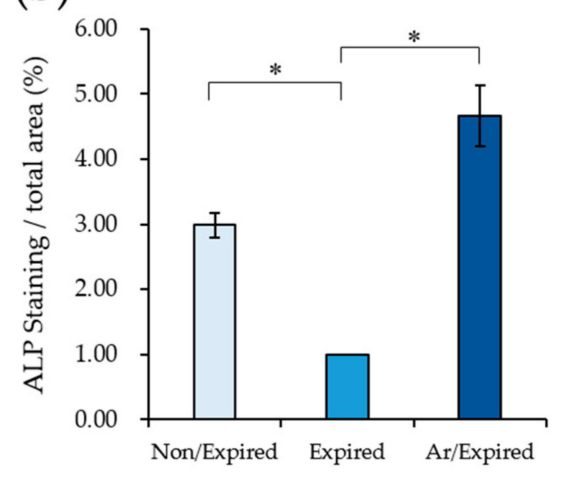

(c)

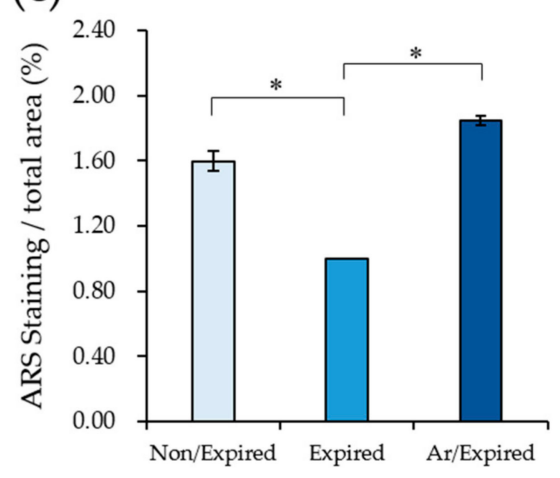

Figure 6. Osteogenic cell differentiation of hMSCs. (a) Alkaline phosphatase (ALP) staining and Alizarin Red S (ARS) staining, (b) ALP quantitative results, (c) ARS quantitative results. The symbol * indicates statistical significance $(p<0.05)$.

\subsubsection{Analysis of Real-Time Polymerase Chain Reaction (PCR)}

The effects of three groups on the osteogenic differentiation of hMSCs were assessed by using real-time PCR analysis. After 4 days of culture, osteogenic transcription factors (Runx2) and osteogenic markers $(A L P, O C N)$ were up regulated in the cells grown in the extracts of $\mathrm{Ar} /$ Expired group compared to the cells cultured in the Non/Expired group and Expired group (Figure 7a-c). On day 8, the osteogenic 
transcription factor $(B M P 2)$ and osteogenic marker $(O P N)$ was up regulated in the cells grown in the $\mathrm{Ar} /$ Expired group than the Non/Expired group and Expired group (Figure 7d,e). Through the results of PCR analysis, treating with Ar-based APP was shown to have an effect on increasing osteogenesis of hMSCs. However, since the expression of RNA decreases faster than that of protein after its translational work is done, there were no statistically significant differences among the three groups at day 4 and 8.
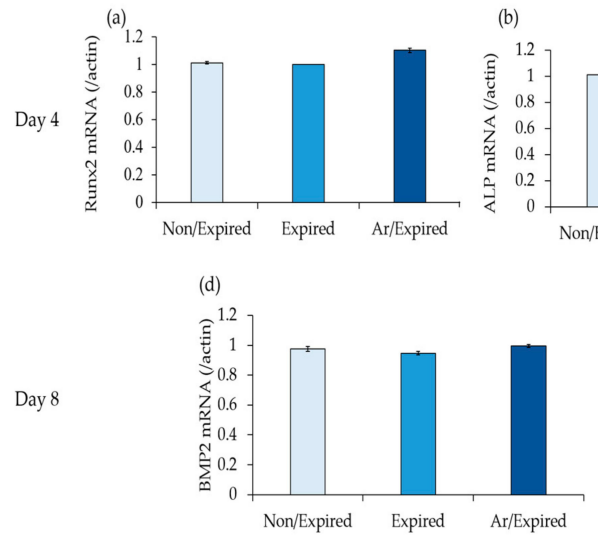
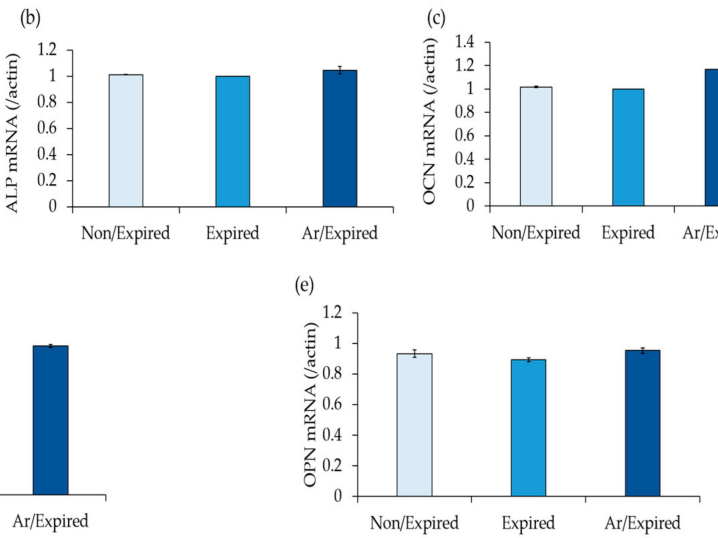

Figure 7. Real-time PCR analysis of hMSCs on Bio-Oss ${ }^{\circledR}$. (a) Runx2, (b) $A L P$, (c) $O C N$, (d) BMP2, (e) $O P N$ were selected as the osteogenic differentiation related genes.

\subsection{In Vivo Study}

\subsubsection{Volumetric Findings}

The volumetric results analyzed using micro-CT were summarized in Table 2 and Figure 8. The micro-CT images showed that bone graft materials were well positioned in the calvarial defects. The new bone volume (\%) of the Non/Expired group, Expired group, and $\mathrm{Ar} /$ Expired group were 17.48 $( \pm 6.22), 14.83( \pm 3.74)$, and $23.05( \pm 6.21)$, respectively. There were no significant differences between groups $(p>0.05)$.

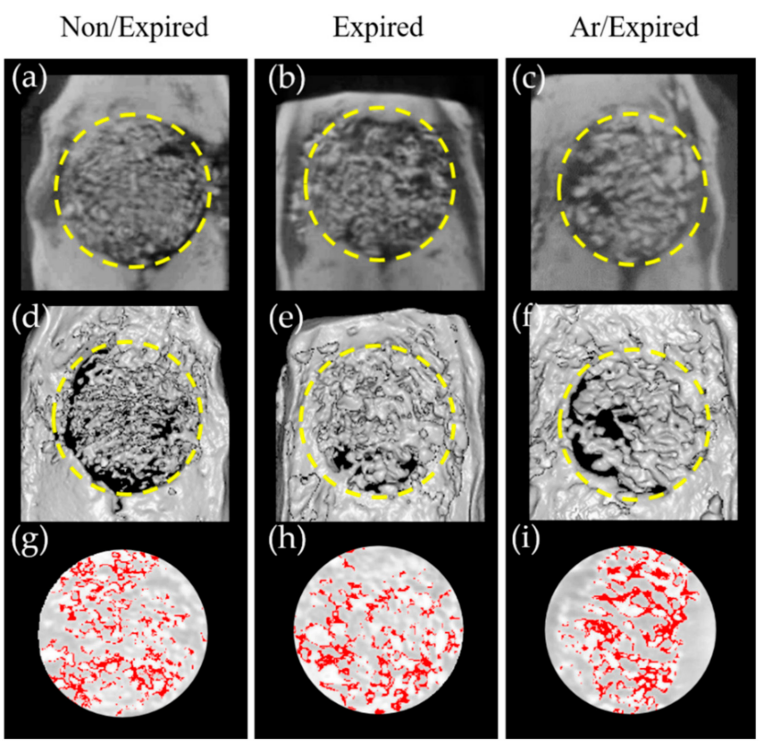

Figure 8. Micro-computed tomographic images of each group. (a,d,g) Non/Expired group, (b,e,h) Expired group, (c,f,i) Ar/Expired group. The radiographical images for rows 1, the 3D reconstructed images for row 2, and the colored images (red; new bone, gray; bone graft) for rows 3. 
Table 2. Mean $( \pm S D)$ values of new bone volume within the ROI (\%).

\begin{tabular}{cc}
\hline Group & New Bone Volume (\%) \\
\hline Non/expired & $17.48 \pm 6.22$ \\
Expired & $14.83 \pm 3.74$ \\
Ar/Expired & $23.05 \pm 6.21$ \\
\hline$p$ value & 0.091 \\
\hline
\end{tabular}

\subsubsection{Histologic and Histometric Findings}

In all the histological specimens, the bone graft materials were well positioned in the defective site (Figures 9 and 10). At 4 weeks after surgery, the early phase of new bone formation was observed around the bone graft materials in calvarial defects in the all groups, but most of the new bone tissues were immature. The bone marrows and connective tissues were filled the defect and detected around the residual bone grafts. More new bones were observed in the Ar/Expired group than in the other experimental groups.

The histometric results of the new bone area percentage were shown in Table 3. The new bone volume (\%) of the Non/Expired group, Expired group, and Ar/Expired group were $12.71( \pm 4.99)$, $13.22( \pm 5.76)$, and $13.77( \pm 10.62)$, respectively. There were no significant differences between groups $(p>0.05)$.

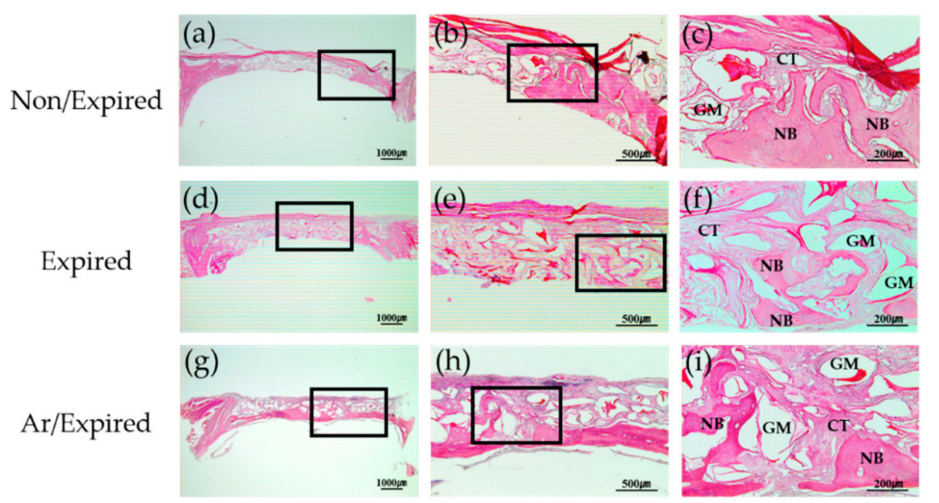

Figure 9. Histological sections of Hematoxylin-Eosin (H\&E) staining. (a-c) Non/Expired group, (d-f) Expired group, (g-i) Ar/Expired group. GM: bone graft material, NB: newly formed bone, OB: old bone, CT: connective tissue. (Original magnifications: $\times 12.5(\mathbf{a}, \mathbf{d}, \mathbf{g}), \times 40(\mathbf{b}, \mathbf{e}, \mathbf{h}),, \times 100(\mathbf{c}, \mathbf{f}, \mathbf{i}))$.

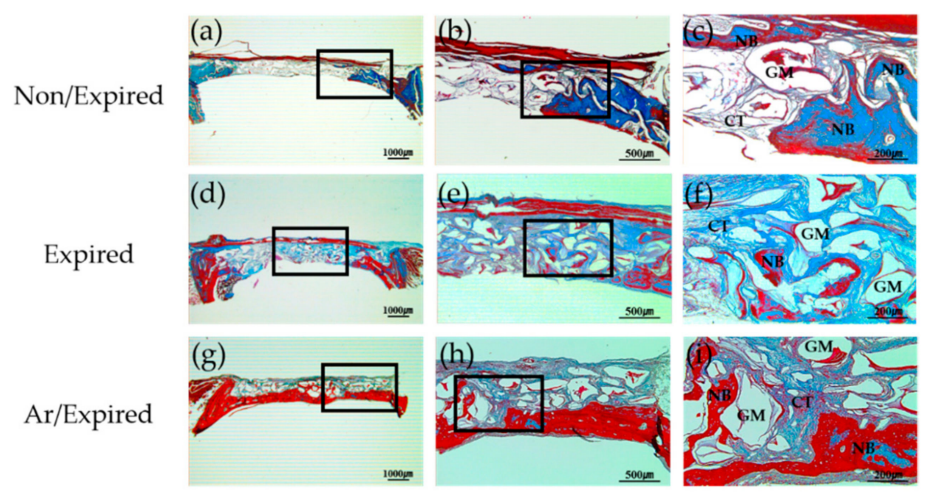

Figure 10. Histological sections of Masson's trichrome (MT) staining. (a-c) Non/Expired group, (d-f) Expired group, (g-i) Ar/Expired group. GM: bone graft material, NB: newly formed bone, OB: old bone, CT: connective tissue. (Original magnifications: $\times 12.5(\mathbf{a}, \mathbf{d}, \mathbf{g}), \times 40(\mathbf{b}, \mathbf{e}, \mathbf{h}), \times 100(\mathbf{c}, \mathbf{f}, \mathbf{i}))$. 
Table 3. Mean $( \pm \mathrm{SD})$ values of new bone area within the region of interest $(\%)$.

\begin{tabular}{cc}
\hline Group & New Bone Volume (\%) \\
\hline Non/expired & $12.71 \pm 4.99$ \\
Expired & $13.22 \pm 5.76$ \\
Ar/Expired & $13.77 \pm 10.62$ \\
$p$ value & 0.091 \\
\hline
\end{tabular}

\section{Discussion}

Bone graft materials have been used to reconstruct a bone defect, and act as a scaffold for new bone formation [32]. The shelf time of a medical product is the length of time that the material retains its properties [11]. Biomaterials have a direct effect on human health, so clinicians should observe the expiry date for the safety and best quality. According to the previous study, it was reported that the hydrophobic state of implant biomaterial resulting from the "aging effect" can change to the hydrophilic surface through the ultraviolet (UV) light treatment of aged implants [12,13]. Recently, a number of studies reported that atmospheric pressure plasma (APP) surface treatment can turn a surface hydrophilic and even enhance biocompatibility and cell responses $[1,16,17,33,34]$. Thus, we expected that the APP treatment can modify the surface of bone graft material by improving surface energy and assumed that such surface treatment can reactivate the expired bone graft material.

The APP is activated by energy from continuous collisions between the molecule of operated gas and electron, and the gas molecules are consequently ionized [35]. This ionized gas adheres to the substrate surface, and this surface modification method induces a chemical and physical response on the substrate surface without inordinate change [35-37]. However, in the SEM analyses of the previous study, there was no remarkable surface difference caused by a physical response between non-treated and Ar-based APP treated bone graft materials [1,27]. Plasma-treated biomaterials in several previous studies exhibited more chemical surface changes than physical changes [24,35]. Choy et al. [1] demonstrated that plasma treatment changes the chemical properties of bone grafts by reducing $C$ species and increasing $C a$ and $P$ species. Similarly, in the results of our surface observation using SEM, the surface morphologies of the Non/Expired and Ar/Expired groups did not show any difference. Moreover, it seems that even if bovine xenografts have passed the 2-year expiration date, the surface changes were not observed in comparison with regular bone grafts.

The hMSC that we used in this research is pluripotent and shows the capability of differentiation into mesenchymal lineages, including vascular smooth muscle (VSMC), dermis, and the skeletal system. hMSC is the most widely used stem cells in many preclinical studies and it is commonly used as an osteo-progenitor cells in osteogenesis studies [38,39]. Numerous studies have demonstrated that physicochemical properties of bioactive materials can control the activities of cells, such as adhesion, proliferation as well as differentiation. Previous investigations have shown that the plasma treatment on the surface of biomaterials enhanced osteogenic differentiation compared to other surfaces [40-43]. In this study, the cells cultured with three different types of Bio-Oss particles showed no significant effect on their proliferation rate. However, the cells of the Ar/Expired group were enhanced in their osteogenic differentiation and mineralization in the results of ALP and ARS staining. Furthermore, subsequent investigation of the expression level of osteogenic marker genes including $A L P, O C N$, $O P N$, Runx2, and BMP2 showed that Ar-plasma facilitated as a potential inducer in osteogenesis of hMSCs. These results suggest that Ar-plasma treatment on Bio-Oss particles could be a promising surface energy and accelerated the initial cellular interaction [27,36]. APP treatment of bone grafts may able to promote the osteogenic differentiation of MSCs, leading to the potential development of bone graft substitutes.

To assess the new bone formation in rat calvarial defect, the micro CT and histomorphometric analyses were done in this in vivo study. Through the result of our cell study, which showed good osteogenic differentiation of hMSCs in the APP treated group, we predicted that Ar-based APP treatment of bone graft materials may increase the new bone formation. However, in our volumetric 
results, there was no significant difference among the groups. Besides, in the measurement of new bone area, the statistical difference was not found among the groups. Several previous studies reported that the new bone regeneration of implants surface modified by APP was higher than that of non-APP treated implants [24,44]. On the other hand, similarly to the present study, Beutel et al. [27] reported that the APP treatment of bone graft materials did not increase the new bone formation. Through the conflicting results, it seems that there might be no appreciable difference in vivo even if plasma surface modification was performed on biomaterials already having high surface energy $[24,27,44]$. The results of this in vivo study exhibited that there is no difference in the new bone formation ability between the non-expired and expired bone graft materials. After the expiration date, the object is normally considered damaged. When a damaged substance enters the body, chemicals, bacteria, are formed, and a biological defense mechanism called inflammation is formed to prevent this [45]. However, in this histologic observation, inflammatory responses (e.g., erythema, edema, and pus) were not detected in any of the rats treated with expired xenografts at 4 weeks after surgery. It could be considered that the 2-year after expiration date did not affect the new bone regeneration ability.

In the present paper, we compared the bone formation capacity of Bio-Oss ${ }^{\circledR}$ with non-expired, expired, and expired grafts treated by Ar-based APP. We could demonstrate that treatment of Ar-based APP on Bio-Oss ${ }^{\circledR}$ gives positive effects on increasing osteogenesis of hMSCs. However, the result of this in vivo study, Bio-Oss ${ }^{\circledR}$ treated by Ar-based APP, did not show higher bone formation ability compared to other groups. Therefore, further studies on finding optimal APP conditions should be carried out constantly. Then we can also conclude that there was no significant difference between expired one and non-expired bone grafts. It seemed that 2-year expiry date did not affect new bone regeneration ability. The reason for using the expired bone grafts that were out of date in this study was just to confirm the APP effect in various conditions of bone grafts. Therefore, above all, the expiration date of bone graft substitutes must be observed in the clinic for ethical and safety issues.

\section{Conclusions}

Within the limitation of this study, treatment of Ar-based APP in bovine xenografts seems to offer the potential to have a better effect on osteogenic cell function. However, our in vivo study showed that the bone regeneration ability of Ar-based APP treated bone grafts was not significantly advanced compared to that of the non-treated group. Even if the study showed that there was no significant difference between the Non/Expired and Expired group, bone grafts that are past their expiration date should not be used for safety and ethical issues.

Author Contributions: Conceptualization, H.-J.K. and J.-B.H.; Data Curation, W.-S.L., H.-J.K. and J.-B.H.; Formal Analysis, J.-J.A. and J.-H.Y.; Methodology, G.-C.K. and J.J.H.; Validation, G.-C.K. and J.J.H.; Writing-Original Draft, J.-J.A., J.-H.Y. and E.-B.B.; Writing-Review and Editing, J.-J.A., J.-H.Y., E.-B.B., W.-S.L., H.-J.K. and J.-B.H.

Funding: This work was supported by the National Research Foundation of Korea(NRF) grant funded by the Korea government(MSIT) (No. 2017R1A2B4005820).

Conflicts of Interest: The authors declare no conflict of interest.

\section{References}

1. Choy, C.S.; Salamanca, E.; Lin, P.Y.; Huang, H.M.; Teng, N.C.; Pan, Y.H.; Chang, W.J. Argon plasma surface modified porcine bone substitute improved osteoblast-like cell behavior. Coatings 2019, 9, 134. [CrossRef]

2. Ana, I.D. Bone Substituting Materials in Dental Implantology. In Bone Management in Dental Implantology; Springer: Berlin, Germany, 2019; pp. 121-141.

3. Hoexter, D.L. Bone regeneration graft materials. J. Oral Implantol. 2002, 28, 290-294. [CrossRef]

4. Greenwald, A.S.; Boden, S.D.; Goldberg, V.M.; Khan, Y.; Laurencin, C.T.; Rosier, R.N. Bone-graft substitutes: Facts, fictions, and applications. JBJS 2001, 83, S98-S103. [CrossRef] [PubMed]

5. Klinge, B.; Alberius, P.; Isaksson, S.; Jönsson, J. Osseous response to implanted natural bone mineral and synthetic hydroxylapatite ceramic in the repair of experimental skull bone defects. J. Oral Maxillofac. Surg. 1992, 50, 241-249. [CrossRef] 
6. Esposito, M.; Grusovin, M.G.; Kwan, S.; Worthington, H.V.; Coulthard, P. Interventions for replacing missing teeth: Bone augmentation techniques for dental implant treatment. Cochrane Database Syst. Rev. 2008, 16, CD003607. [CrossRef]

7. Amerio, P.; Vianale, G.; Reale, M.; Muraro, R.; Tulli, A.; Piattelli, A. The effect of deproteinized bovine bone on osteoblast growth factors and proinflammatory cytokine production. Clin. Oral Implants Res. 2010, 21, 650-655. [CrossRef] [PubMed]

8. Pinholt, E.M.; Bang, G.; Haanaes, H.R. Alveolar ridge augmentation in rats by Bio-Oss. Eur. J. Oral Sci. 1991, 99, 154-161. [CrossRef] [PubMed]

9. Denissen, H.; De Groot, K.; Makkes, P.C.; Van den Hooff, A.; Klopper, P. Tissue response to dense apatite implants in rats. J. Biomed. Mater. Res. 1980, 14, 713-721. [CrossRef] [PubMed]

10. Council on Dental Materials, Instruments, and Equipment. ANSI/ADA specification no. $33^{*}$ for dental terminology. J. Am. Dent. Assoc. 1984, 109, 89. [CrossRef]

11. Bajaj, S.; Singla, D.; Sakhuja, N. Stability testing of pharmaceutical products. J. App. Pharm. Sci. 2012, 2, 129-138.

12. Li, S.; Ni, J.; Liu, X.; Zhang, X.; Yin, S.; Rong, M.; Guo, Z.; Zhou, L. Surface characteristics and biocompatibility of sandblasted and acid-etched titanium surface modified by ultraviolet irradiation: An in vitro study. J. Biomed. Mater. Res. Part B Appl. Biomater. 2012, 100, 1587-1598. [CrossRef] [PubMed]

13. Hori, N.; Ueno, T.; Suzuki, T.; Iwasa, F.; Yamada, M.; Att, W.; Okada, S.; Ohno, A.; Aita, H.; Kimoto, K. Ultraviolet light treatment for the restoration of age-related degradation of titanium bioactivity. Int. J. Oral Maxillofac. Implant. 2010, 25, 49-62.

14. Al Qahtani, M.S.; Wu, Y.; Spintzyk, S.; Krieg, P.; Killinger, A.; Schweizer, E.; Stephan, I.; Scheideler, L.; Geis-Gerstorfer, J.; Rupp, F. UV-A and UV-C light induced hydrophilization of dental implants. Dent. Mater. 2015, 31, e157-e167. [CrossRef] [PubMed]

15. Kim, H.S.; Lee, J.I.; Yang, S.S.; Kim, B.S.; Kim, B.C.; Lee, J. The effect of alendronate soaking and ultraviolet treatment on bone-implant interface. Clin. Oral Implant. Res. 2017, 28, 1164-1172. [CrossRef]

16. Puligundla, P.; Mok, C. Potential applications of nonthermal plasmas against biofilm-associated micro-organisms in vitro. J. Appl. Microbiol. 2017, 122, 1134-1148. [CrossRef]

17. Guastaldi, F.P.; Yoo, D.; Marin, C.; Jimbo, R.; Tovar, N.; Zanetta-Barbosa, D.; Coelho, P.G. Plasma treatment maintains surface energy of the implant surface and enhances osseointegration. Int. J. Biomater. 2013, 2013, 354125. [CrossRef]

18. De Geyter, N.; Morent, R. Nonthermal plasma sterilization of living and nonliving surfaces. Annu. Rev. Biomed. Eng. 2012, 14, 255-274. [CrossRef]

19. Fridman, G.; Friedman, G.; Gutsol, A.; Shekhter, A.B.; Vasilets, V.N.; Fridman, A. Applied plasma medicine. Plasma Process. Polym. 2008, 5, 503-533. [CrossRef]

20. Heo, N.S.; Lee, M.K.; Kim, G.W.; Lee, S.J.; Park, J.Y.; Park, T.J. Microbial inactivation and pesticide removal by remote exposure of atmospheric air plasma in confined environments. J. Biosci. Bioeng. 2014, 117, 81-85. [CrossRef]

21. Kim, J.H.; Lee, M.A.; Han, G.J.; Cho, B.H. Plasma in dentistry: A review of basic concepts and applications in dentistry. Acta Odontol. Scand. 2014, 72, 1-12. [CrossRef]

22. Chu, P.K.; Chen, J.; Wang, L.; Huang, N. Plasma-surface modification of biomaterials. Mater. Sci. Eng. R Rep. 2002, 36, 143-206. [CrossRef]

23. Jimbo, R.; Sawase, T.; Baba, K.; Kurogi, T.; Shibata, Y.; Atsuta, M. Enhanced initial cell responses to chemically modified anodized titanium. Clin. Implant Dent. Relat. Res. 2008, 10, 55-61. [CrossRef] [PubMed]

24. Teixeira, H.S.; Marin, C.; Witek, L.; Freitas, A., Jr.; Silva, N.R.; Lilin, T.; Tovar, N.; Janal, M.N.; Coelho, P.G. Assessment of a chair-side argon-based non-thermal plasma treatment on the surface characteristics and integration of dental implants with textured surfaces. J. Mech. Behav. Biomed. Mater. 2012, 9, 45-49. [CrossRef] [PubMed]

25. Elias, A.B.; Simão, R.A.; Prado, M.; Cesar, P.F.; Dos Santos, G.B.; Da Silva, E.M. Effect of different times of nonthermal argon plasma treatment on the microtensile bond strength of self-adhesive resin cement to yttria-stabilized tetragonal zirconia polycrystal ceramic. J. Prosthet. Dent. 2019, 121, 485-491. [CrossRef] [PubMed]

26. Mauer, G.; Vaßen, R.; Stöver, D. Atmospheric plasma spraying of yttria-stabilized zirconia coatings with specific porosity. Surf. Coat. Technol. 2009, 204, 172-179. [CrossRef] 
27. Beutel, B.G.; Danna, N.R.; Gangolli, R.; Granato, R.; Manne, L.; Tovar, N.; Coelho, P.G. Evaluation of bone response to synthetic bone grafting material treated with argon-based atmospheric pressure plasma. Mater. Sci. Eng. C 2014, 45, 484-490. [CrossRef]

28. Niaounakis, M. Biopolymers: Processing and Products; William Andrew: New York, NY, USA, 2014.

29. Cools, P.; Asadian, M.; Nicolaus, W.; Declercq, H.; Morent, R.; De Geyter, N. Surface treatment of PEOT/PBT $(55 / 45)$ with a dielectric barrier discharge in air, helium, argon and nitrogen at medium pressure. Materials 2018, 11, 391. [CrossRef]

30. Giro, G.; Tovar, N.; Witek, L.; Marin, C.; Silva, N.R.; Bonfante, E.A.; Coelho, P.G. Osseointegration assessment of chairside argon-based nonthermal plasma-treated Ca-P coated dental implants. J. Biomed. Mater. Res. Part A 2013, 101, 98-103. [CrossRef]

31. Canullo, L.; Genova, T.; Naenni, N.; Nakajima, Y.; Masuda, K.; Mussano, F. Plasma of argon enhances the adhesion of murine osteoblasts on different graft materials. Ann. Anat. Anat. Anz. 2018, 218, 265-270. [CrossRef]

32. Nasr, H.F.; Aichelmann-Reidy, M.E.; Yukna, R.A. Bone and bone substitutes. Periodontol. 2000 1999, $19,74-86$. [CrossRef]

33. Khurana, K.; Müller, F.; Jacobs, K.; Faidt, T.; Neurohr, J.U.; Grandthyll, S.; Mücklich, F.; Canal, C.; Ginebra, M.P. Plasma polymerized bioceramics for drug delivery: Do surface changes alter biological behaviour? Eur. Polym. J. 2018, 107, 25-33. [CrossRef]

34. Genova, T.; Pesce, P.; Mussano, F.; Tanaka, K.; Canullo, L. The influence of bone-graft bio-functionalization with plasma of argon on bacterial contamination. J. Biomed. Mater. Res. Part A 2019, 107, 67-70. [CrossRef] [PubMed]

35. Liu, Y.C.; Hsieh, J.P.; Chen, Y.C.; Kang, L.L.; Hwang, C.S.; Chuang, S.F. Promoting porcelain-zirconia bonding using different atmospheric pressure gas plasmas. Dent. Mater. 2018, 34, 1188-1198. [CrossRef] [PubMed]

36. Duske, K.; Koban, I.; Kindel, E.; Schröder, K.; Nebe, B.; Holtfreter, B.; Jablonowski, L.; Weltmann, K.D.; Kocher, T. Atmospheric plasma enhances wettability and cell spreading on dental implant metals. J. Clin. Periodontol. 2012, 39, 400-407. [CrossRef]

37. Foest, R.; Kindel, E.; Ohl, A.; Stieber, M.; Weltmann, K. Non-thermal atmospheric pressure discharges for surface modification. Plasma Phys. Control. Fusion 2005, 47, B525-B536. [CrossRef]

38. Trounson, A.; McDonald, C. Stem cell therapies in clinical trials: Progress and challenges. Cell Stem Cell 2015, 17, 11-22. [CrossRef]

39. Krampera, M.; Pizzolo, G.; Aprili, G.; Franchini, M. Mesenchymal stem cells for bone, cartilage, tendon and skeletal muscle repair. Bone 2006, 39, 678-683. [CrossRef]

40. Waser-Althaus, J.; Salamon, A.; Waser, M.; Padeste, C.; Kreutzer, M.; Pieles, U.; Müller, B.; Peters, K. Differentiation of human mesenchymal stem cells on plasma-treated polyetheretherketone. J. Mater. Sci. Mater. Med. 2014, 25, 515-525. [CrossRef]

41. Barradas, A.M.; Lachmann, K.; Hlawacek, G.; Frielink, C.; Truckenmoller, R.; Boerman, O.C.; Van Gastel, R.; Garritsen, H.; Thomas, M.; Moroni, L. Surface modifications by gas plasma control osteogenic differentiation of MC3T3-E1 cells. Acta Biomater. 2012, 8, 2969-2977. [CrossRef]

42. Liu, W.; Cai, Q.; Zhang, F.; Wei, Y.; Zhang, X.; Wang, Y.; Deng, X.; Deng, X. Dose-dependent enhancement of bone marrow stromal cells adhesion, spreading and osteogenic differentiation on atmospheric plasma-treated poly (L-lactic acid) nanofibers. J. Bioact. Compat. Polym. 2013, 28, 453-467. [CrossRef]

43. Lin, C.H.; Lee, S.Y.; Lin, Y.M. Plasma treatment in conjunction with EGM-2 medium increases endothelial and osteogenic marker expressions of bone marrow mesenchymal stem cells. J. Mater. Sci. 2016, 51, 9145-9154. [CrossRef]

44. Coelho, P.G.; Giro, G.; Teixeira, H.S.; Marin, C.; Witek, L.; Thompson, V.P.; Tovar, N.; Silva, N.R. Argon-based atmospheric pressure plasma enhances early bone response to rough titanium surfaces. J. Biomed. Mater. Res. Part A 2012, 100, 1901-1906. [CrossRef] [PubMed]

45. Medzhitov, R.; Janeway, C.A., Jr. Innate immunity: Impact on the adaptive immune response. Curr. Opin. Immunol. 1997, 9, 4-9. [CrossRef]

(C) 2019 by the authors. Licensee MDPI, Basel, Switzerland. This article is an open access article distributed under the terms and conditions of the Creative Commons Attribution (CC BY) license (http://creativecommons.org/licenses/by/4.0/). 